\title{
Torque, myoeletric sygnal and heart rate responses during concentric and eccentric exercises in older men
}

\author{
Torque, sinal eletromiográfico e respostas da frequência cardíaca durante \\ exercícios concêntrico e excêntrico em homens idosos
}

Robison J. Quitério',2, Ruth C. Melo', Anielle C. M. Takahashi', Isabela A. V. Aniceto', Ester Silva',3, Aparecida M. Catai'

\begin{abstract}
Background: The literature reports that the eccentric muscular action produces greater force and lower myoelectric activity than the concentric muscular action, while the heart rate (HR) responses are bigger during concentric contraction. Objectives: To investigate the maximum average torque (MAT), surface electromyographic (SEMG) and the heart rate (HR) responses during different types of muscular contraction and angular velocities in older men. Methods: Twelve healthy men $(61.7 \pm 1.6 y e a r s)$ performed concentric $(C)$ and eccentric (E) isokinetic knee extension-flexion at $60 \%$ s and $120 \%$ s. SEMG activity was recorded from vastus lateralis muscle and normalized by Root Mean Square - RMS $(\mu \mathrm{V})$ of maximal isometric knee extension at $60^{\circ}$. HR (beats/min) and was recorded at rest and throughout each contraction. The data were analyzed by the Friedman test for repeated measures with post hoc Dunn's test $(p<0.05)$. Results: The median values of MAT $(\mathrm{N} . \mathrm{m} / \mathrm{kg})$ was smaller and the RMS $(\mu \mathrm{V})$ was larger during concentric contraction $\left(\mathrm{C} 60^{\circ} / \mathrm{s}=2.80\right.$ and $0.99 ; \mathrm{C} 120 \% \mathrm{~s}=2.46$ and 1.0$)$ than eccentric $(E 60 \%=3.94$ and $0.85 ; E 120 \% \mathrm{~s}=4.08$ and 0.89$)$, respectively. The HR variation was similar in the four conditions studied. Conclusion: The magnitude of MAT and RMS responses in older men were dependent of the nature of the muscular action and independent of the angular velocity, whereas HR response was not influenced by these factors.
\end{abstract}

Key words: elderly; heart rate; isokinetic; exercise; surface electromyography.

\section{Resumo}

Contextualização: A literatura refere que a ação muscular excêntrica produz maior força e menor atividade mioelétrica que a concêntrica, enquanto a resposta da frequência cardíaca (FC) é maior durante a contração concêntrica que durante a excêntrica. Objetivos: Investigar as respostas de torque médio máximo (TMM), eletromiografia de superfície (EMGs) e FC durante diferentes tipos de contração muscular e velocidades angulares em homens idosos. Materiais e métodos: Doze homens saudáveis $(61,7 \pm 1,6$ anos) realizaram flexões e extensões do joelho concêntrica (C) e excêntrica (E) em $60 \%$ e $120 \%$ s. Registrou-se a atividade EMGs do músculo vasto lateral e normalizou-se pela RMS $(\mu \mathrm{V})$ da extensão isométrica máxima do joelho em $60^{\circ}$. A FC (bpm) foi registrada em repouso e durante cada contração. Os dados foram analisados utilizando-se o teste de Friedman para medidas repetidas com post hoc de Dunn $(\mathrm{p}<0,05)$. Resultados: Os valores médios de TMM $(\mathrm{N} . \mathrm{m} / \mathrm{kg})$ foram menores e os de RMS $(\mu \mathrm{V})$ foram maiores $(p<0,05)$ nas contrações concêntricas $(C 60 \%=2,80$ e 0,99; $C 120 \% s=2,46$ e 1,0) comparativamente com as excêntricas $(E 60 \%=3,94$ e 0,85; $E 120 \%$ s=4,08 e 0,89), respectivamente. Já a variação da FC foi semelhante nas quatro condições estudadas. Conclusão: A magnitude das respostas de TMM e RMS em homens idosos foi dependente da natureza da ação muscular e independente da velocidade angular, enquanto as respostas da FC não foram influenciadas por esses fatores.

Palavras-chave: idoso; frequência cardíaca; isocinético; exercício; eletromiografia de superfície.

Received: 08/07/2009 - Revised: 30/04/2010 - Accepted: 13/10/2010

${ }^{1}$ Physical Therapy Department, Universidade Federal de São Carlos (UFSCar), São Carlos, SP, Brazil

${ }^{2}$ Special Education Department, Universidade Estadual Paulista "Julio de Mesquita Filho" (UNESP), Marilia, SP, Brazil

${ }^{3}$ Faculty of Health Sciences, Universidade Metodista de Piracicaba (UNIMEP), Piracicaba, SP, Brazil

Correspondence to: Aparecida Maria Catai, Núcleo de Pesquisa em Exercício Físico, Departamento de Fisioterapia, Universidade Federal de São Carlos, Rodovia Washington Luis, km 235

Caixa Postal 676, CEP 13565-905, São Carlos, SP, Brasil, e-mail: mcatai@ufscar.br 


\section{Introduction $: \because$.}

The age-related decrease in total muscle mass is referred as sarcopenia. This reduction is more accentuated in type II fibers, which is considered a direct cause of decreased muscular strength and power ${ }^{1}$, mainly during muscular concentric action $^{2,3}$. Although the eccentric action produces greater force than the concentric ${ }^{2,4-12}$, some electromyographic evidence suggests that during eccentric activity neural inhibition occurs (i.e., the muscular fibers are not totally activated) and, consequently, there is a lower myoelectrical activity ${ }^{10,11,13}$.

The literature reports that torque magnitude is also influenced by angular velocity, since during concentric exercise, a decrease in maximum voluntary torque is observed as consequence of higher angle acceleration for young $g^{2,6-8,14-17}$ and older subjects ${ }^{18}$. On the other hand, there are conflicting results about angular velocity during eccentric action as different studies have found that torque development during eccentric actions remains simi$\operatorname{lar}^{2}$ or increases from slow to fast angular velocities ${ }^{5,19,20}$.

Concerning the influences of angular velocity on electromyography (EMG) signals, there are conflicting results in the literature. Some studies with young participants report that the EMG signals has a direct and an inverse relationship with the concentric and eccentric contractions, respectively ${ }^{5,7}$. In contrast, other authors suggest that the myoelectric signals are not influenced by the angular velocity during both concentric and eccentric actions ${ }^{15,21,22}$.

The adjustments of the cardiovascular system during the exercise are also dependent on the increase of the recruitment of muscular fibers. With the increase of the metabolic demands of the muscles in activity the mechanisms of control of the central nervous system, neural reflex and cardiovascular act togheter ${ }^{23}$ to guarantee the necessary levels of oxygen and nutrients to the metabolism as well as to remove of catabolic products. This process of adjustment is associated with the action of afferent fibers of groups III and IV, that the main function is to send mechanical and metabolic information, in the muscular level, to the central nervous system. This information reach the area of cardiovascular control, located in the bulb, and by means of the autonomic nervous system and its afferents sympathetic and parasympathetic modulates the heart rate (HR) in accordance with the mechanics and metabolic demand imposed, increasing the number of heart beats ${ }^{23,24}$.

The magnitude of $\mathrm{HR}$ response to isokinetic exercise is related to the intensity of the maximum tension, size of the mass of the contracting muscle group and time of muscular action. Since performed at the same intensity and for a long period of time, concentric contraction performed by young men produces greater HR elevation than eccentric contraction does, 2,3,10,25-29. This characteristic is attributed to a low muscular metabolic demand required to perform the eccentric contraction, which has an important contribution from the passive tissues in torque generation ${ }^{2,3}$. In addition, the magnitude of $\mathrm{HR}$ responses is not influenced by the angular velocity of the concentric and eccentric contractions ${ }^{14}$ performed within short periods.

Therefore our hypothesis are that there are differences in myoelectric activity between the concentric and eccentric contractions when performed at same angular velocity, however the HR responses is not influenced by the type of contraction and angular velocity when the exercise is performed within the same tension in short periods ${ }^{14}$. Thus, the purpose of the present study was to investigate the influence of the concentric and eccentric contraction performed at the two angular velocities, on torque, myoeletrical signal and HR response in healthy older men.

It is important to highlight that studies that recruited old participants and have used the variables selected for this investigation were not found. Therefore this investigation is relevant for the professionals that act in the rehabilitation area as well as the ones that works with prescription of physical exercise for old people; a population that is increasing worldwide.

\section{Methods $\because \because$.}

\section{Subjects}

Twenty eight older men were interviewed and were considered eligible for the study. From those only. twelve volunteers $(61.7 \pm 1.6$ years old $)$ confirmed their good health by the clinical and physical examination and laboratory tests. These tests included a standard electrocardiogram (ECG), maximum exercise test conducted by physician, chest X-ray, total blood count, urinalysis and clinical biochemical screen test and were recruited for this study. Subjects were excluded if they were currently smoking or were taking any type of medication. They were informed about the experimental procedures and signed an informed consent form, protocol number 069/2003, approved by the Ethics Committee of the Universidade Federal de São Carlos (UFSCar), São Carlos, SP, Brazil. All subjects were evaluated at the same time of day, starting from $2 \mathrm{pm}$, in order to take into account the different responses due to circadian changes. The experiments were carried out in a climatically controlled room at $22-23^{\circ} \mathrm{C}$ and relative air humidity at $50-60 \%$. Before the day of the experiment, the subjects were taken to the experimental room for familiarization with the procedures and the equipment to be used. Each subject had been told to avoid caffeinated and alcoholic beverages and to not perform moderate or heavy exercises on the day before the application of the 
protocols. Before beginning the test on each experimental day, the subjects were interviewed and examined to confirm their state of good health and to confirm that the control conditions (HR and systemic blood pressure) were within the normal range. Prior to the test, the subjects performed a three-minute light warm-up on a cycle ergometer followed by 3 sets of 15 seconds of stretching the quadriceps and hamstring muscles.

\section{Peak Oxygen Uptake $\left(\mathrm{VO}_{2 \text { peak }}\right)$}

In order to characterize the aerobic functional capacity of the subjects, the $\mathrm{VO}_{2 \text { peak }}$ was determined during an incremental cycle ergometer (Corival 400, Quinton, Seatle, WA, USA) exercise to exhaustion using a specific metabolic analyzer (CPX-D, Medical Graphics, St Paul, MN, USA).

\section{Isokinetic torque}

The experimental protocol was carried out on an isokinetic dynamometer (Biodex Multi Joint System III, Biodex Medical System Inc., Shirley, NY, USA). The protocol test included three sets of 5 and 8 maximal knee extension/flexion repetitions at $60 \%$ and $120^{\circ} / \mathrm{s}$, respectively, for each tested action (concentric and eccentric) through a range from $90^{\circ}$ to $30^{\circ}$ knee flexion, in a random order, separated by at least 120 -second rest intervals. Additionally, the subjects also performed three sets of maximal voluntary isometric peak force knee extension at $60^{\circ}$ for dominant limb, which was carried out in order to normalize the EMG signals of the isokinetic tests. After warming up the participants seated on the dynamometer chair with the back slightly reclined $\left(85^{\circ}\right)$ and then the subjects were stabilized using straps on the pelvis, chest and thighs. During the maximal efforts trials, they were motivated with visual feedback and consistent verbal encouragement. In addition, the subjects were oriented to avoid the Valsalva's maneuver and to breathe spontaneously (i.e., to not hold their breath during the effort) ${ }^{20}$.

The mean of the maximum torque (Nm) of the all repetitions was calculated and a unique value for each test was determined by the sum of the mean of the extension and flexion contraction. Furthermore, the maximal average torque values were normalized by the individual body weight $(\mathrm{Nm} / \mathrm{kg})^{30}$.

\section{EMG activity}

During the experimental protocol, the EMG activity from the vastus lateralis was recorded by means of bipolar passive $\mathrm{Ag} / \mathrm{AgCl}$ surface electrodes (Noraxon Dual Electrodes, Noraxon USA, Scottsdale, AZ, USA) with an inter-electrode distance (center to center) of two centimeters. All the subjects were prepared for EMG electrode placement by shaving the skin at electrode site and abrading with absorbent cotton and alcohol. The recording electrodes were placed over the center of the belly of the vastus lateralis and oriented longitudinally to the muscular fibers as recommended by Surface Electromyography for the Non-Invasive Assessment of Muscles (SENIAM) ${ }^{31}$ and the reference electrode was attached on the wrist of the opposite arm. The EMG signal was pre amplified (x1000) and filtered (bandpass 20-500 Hz) with an EMG processor (EMG800C, EMG System do Brasil, São José dos Campos, SP, Brazil) (Common Mode Rejection Ratio $>100 \mathrm{~dB}$; input impedance $=10^{9} \mathrm{ohms}$; noise ratio $<3 \mu \mathrm{V}$ RMS). The signal was further sampled and converted to digital form at a rate of $1000 \mathrm{~Hz}$ using a $12 \mathrm{bit} \mathrm{A} / \mathrm{D}$ converter.

EMG signals were quantified by way of the root mean square (RMS), which was normalized (i.e. expressed as percentages), to the mean values of the maximal voluntary isometric contraction ${ }^{32}$ of knee extension at $60^{\circ}$. The mean of the RMS values of the three sets for each test was calculated as the final measurement value.

\section{Heart rate}

During the experimental protocol, the subjects were monitored at the CM5 lead to register the HR and R-R intervals. The ECG and HR were obtained from a one-channel heart monitor (TC 500, ECAFIX, São Paulo, SP, Brazil) and processed using an analog-digital converter Lab.PC+ (National Instruments, Co., Austin, TX, USA). Subsequently, the R-R interval (ms) was calculated on a beat-to-beat basis using specific software ${ }^{33}$. Then, the HR was registered before ( $60 \mathrm{sec}$. of rest), during, and after (120 sec. of recovery) each exercise repetition.

HR (beats per minute) variation was calculated by the difference between the highest HR value verified at the effort ending and the mean value of the resting HR (i.e., the HR values obtained before each test). The arithmetic mean of the HR variation of the three sets for each test was calculated as the final measurement value.

\section{Statistical analysis}

The data were analyzed by the Friedman test for repeated measures and, when appropriated, Dunn's test was utilized. The level of significance was set at $\mathrm{p}<0.05$.

\section{Results $: \because$.}

The characteristics of the subjects studied are presented in Table 1.

The mean of maximum torque $(\mathrm{Nm} / \mathrm{kg})$ of both of the eccentric tests were higher than the concentric tests $(\mathrm{p}<0.05)$. 
Table 1. Characteristics of subjects.

\begin{tabular}{lcc}
\hline & Mean & SD \\
\hline Age (years) & 61.7 & \pm 1.6 \\
\hline Height $(\mathrm{cm})$ & 1.68 & \pm 0.05 \\
\hline Weight $(\mathrm{kg})$ & 71.97 & \pm 5.94 \\
\hline BMl $\left(\mathrm{kg} / \mathrm{m}^{2}\right)$ & 25.33 & \pm 1.23 \\
\hline Resting Heart Rate $(\mathrm{bpm})$ & 65 & \pm 8.52 \\
\hline Resting SBP $(\mathrm{mmHg})$ & 121.66 & \pm 9.45 \\
\hline Resting DBP $(\mathrm{mmHg})$ & 81.66 & \pm 6.54 \\
\hline $\mathrm{VO}_{2 \text { peak }}\left(\mathrm{mLO}_{2} \cdot \mathrm{kg}^{-1} \cdot \mathrm{min}^{-1}\right)$ & 25.59 & \pm 6.17 \\
\hline
\end{tabular}

Data are reported as means $\pm \mathrm{SD}$. BMI=body mass index; $\mathrm{SBP}=$ systolic blood pressure; $\mathrm{DBP}=$ diastolic blood pressure; $\mathrm{VO}_{\text {2pak }}=$ peak of oxygen uptake.

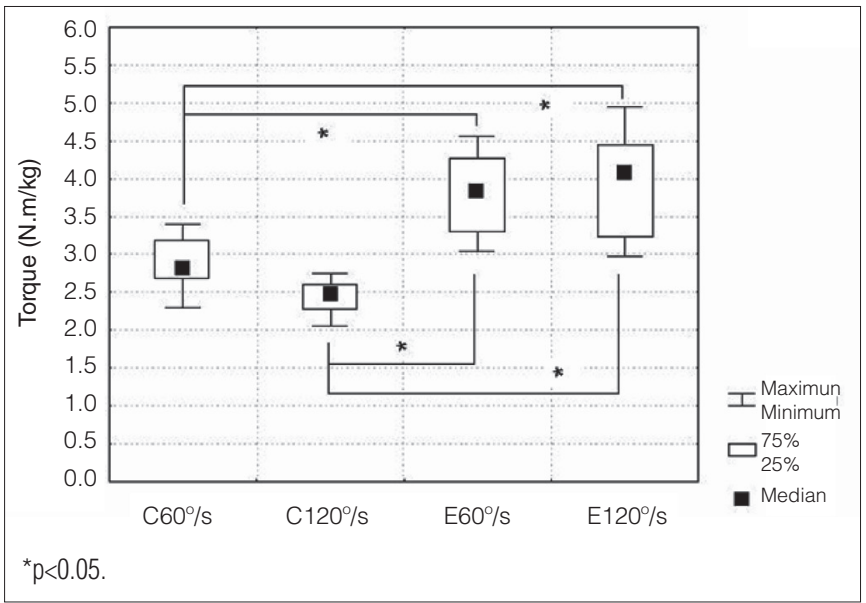

Figure 1. Data of normalized maximum average torque $(\mathrm{N} . \mathrm{m} / \mathrm{kg})$ obtained during concentric exercise at 600/s (C60o/s) and 1200/s (C1200/s), eccentric at 600/s (E60o/s) and 1200/s (E1200/s).

However, no differences were observed for mean of maximum torque between the velocities tested $\left(60^{\circ} / \mathrm{s}\right.$ vs. $\left.120^{\circ} / \mathrm{s}\right)$ for each type of contraction (Figure 1).

The normalized RMS amplitude data of the vastus lateralis obtained during the concentric contraction were higher than the eccentric $(\mathrm{p}<0.05)$. However, no differences were observed for the normalized RMS, between the velocities tested $\left(60^{\circ} / \mathrm{s}\right.$ vs. $120^{\circ} / \mathrm{s}$ ) for each type of contraction (Figure 2).

The HR responses were similar for all tested conditions ( $>0.05)$ (Figure 3).

\section{Discussion $\because:$.}

The present study investigated the influence of the concentric and eccentric contractions performed at two angular velocities, on torque, myoeletrical signal and HR responses of healthy older men. The results of this study demonstrated that the magnitude of MAT and RMS responses in older men were dependent on the type of muscular action and independent

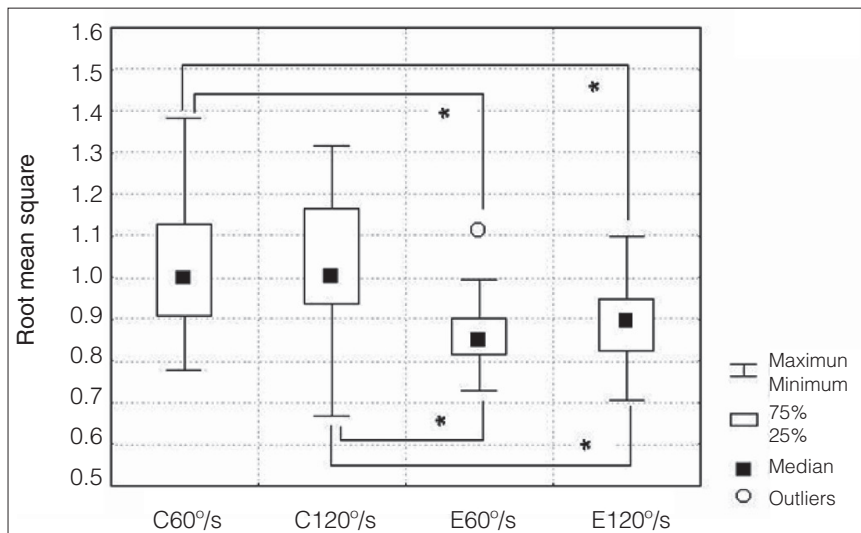

${ }^{*} p<0.05$.

Figure 2. Data of normalized RMS of the vastus lateralis obtained during concentric exercise at 600/s (C60o/s) and 1200/s (C120o/s), eccentric at 600/s (E600/s) and 1200/s (E1200/s).

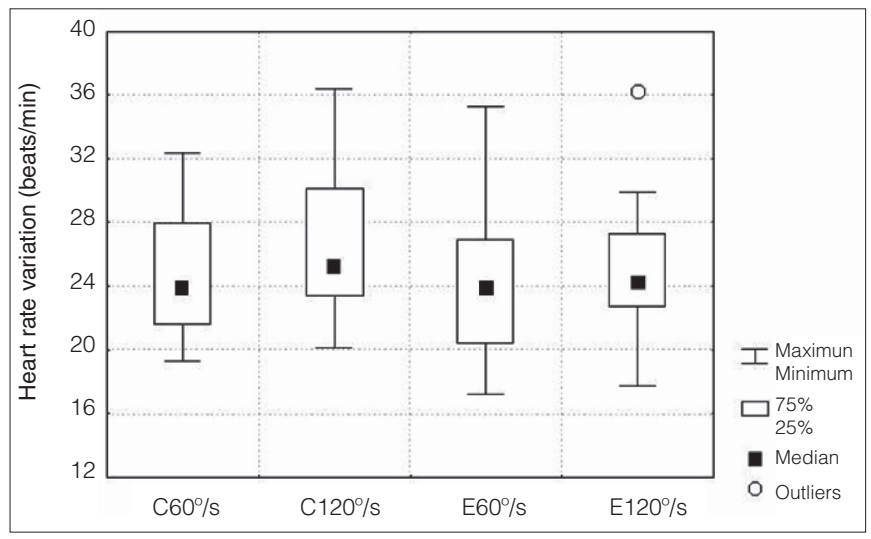

Figure 3. Heart rate variation ( $\triangle \mathrm{HR}-$ beats/min) during concentric exercise at 600/s (C60o/s) and 1200/s (C1200/s), eccentric at 600/s (E60o/s) and 1200/s (E1200/s).

of angular velocity, whereas HR responses was not influenced by any of these factors. The present results are very important because contribute to the knowledge regarding the influence of the muscular activity on the magnitude of the HR responses during eccentric and concentric exercises which has implications for rehabilitation and training, leading to a safer prescription of exercise from the cardiovascular point of view.

In relation to the type of contraction, our results are in accordance with the literature, which reports that during eccentric action, higher torque values were observed ${ }^{2,4-12,19}$ despite the lower EMG values ${ }^{5,9,11}$ when compared to concentric action. These results could be attributed to the additional contribution of the elastic components to force generation during eccentric contraction ${ }^{19}$ and the higher unit motor activation during the concentric contraction ${ }^{9}$. A neural inhibitory mechanism that prevents force increase during concentric maximal voluntary efforts, such as muscle spindles, joint receptors and Golgi tendon organs, may be a factor produced to prevent injury ${ }^{9}$. In particular, one 
of the two impulses originated in the Golgi tendon organs elicits the co-activation of the antagonist muscles ${ }^{34}$, which may be an additional factor responsible for greater torque exerted under eccentric compared to concentric action as well as significantly lower antagonistic EMG activity during eccentric contraction ${ }^{5}$. In addition, the eccentric actions involve a continuous formation and breakage of the crossbridges occurring prior to the ATP release and requiring more force than the normal formation of the crossbridges during concentric actions ${ }^{35}$. The changes in neural drive confirm the existence of the regulatory-tension mechanisms in the preservation of the muscle integrity. Thus, this mechanisms making maximal efficiency between neural drive and intrinsic muscular characteristics ${ }^{36}$.

Some authors ${ }^{2,6,19}$ suggest that torque and angular velocities are directly related in eccentric action, with the inverse occurring for the concentric action. However, in the present study, no differences were observed between the torque values of the two velocities studied (i.e., $60 \%$ s and $120^{\circ} / \mathrm{s}$ ) which is in accordance with the literature which reports that angular velocity does not exert influence on force generation during concentric $^{23,37}$ and eccentric actions ${ }^{2,7,16}$.

Concerning myoelectrical activity, Babault et al. ${ }^{36}$, studying young subjects, observed a lower motor unit activation level during the concentric exercise at $60^{\circ} / \mathrm{s}$. with respect to concentric at $120^{\circ} \mathrm{s}$. However, the authors did not find statistical differences between the mean values of RMS at the two different angular velocities. The increases on the EMG activity and decreases of the torque at faster concentric speeds, indicates a decreasing force exerted by crossbridges with increasing angular velocity ${ }^{5}$ and decreased EMG activity at fast eccentric and slow concentric tests may suggest that the central nervous system is not activated during these particular isokinetic maximal voluntary efforts ${ }^{19}$. Then, the neural inhibitory mechanism discussed above may be one factor responsible for these observations. However, the present results regarding the torque-velocity influence on the magnitude of myoelectrical signals were in accordance with the literature ${ }^{15,21,22}$, since we did not observe the influence of the angular velocities studied (i.e, $60^{\circ} / \mathrm{s}$ and $120 \%$ s on the myoelectrical activity, during the concentric and eccentric actions). These results could be due to the experimental protocol utilized in this study and the angular velocities applied ${ }^{17}$. As well, the similarities observed in the torque and EMG activity, despite the two different velocities, could be also related to the aging process since it is accompanied by muscular fiber loss (mainly type II fibers) which is directly correlated to the EMG signal. This finding indicates that the lower firing rates of the motor units, resulting from age-related neuromuscular changes ${ }^{37}$, or the EMG signal was not sensible to identify this adaptations in older men during dynamic contractions ${ }^{37,38}$ given the small differences between the two studied velocities.

Regarding the heart rate, responses were similar in all tests performed, and the HR was not influenced by the physiological and mechanical differences of concentric and eccentric contractions. These results are in accordance with Haennel et al. ${ }^{14}$ and Overend et al. ${ }^{39}$ and are in conflict with others ${ }^{23,25-28}$ which verified higher HR values during concentric rather than eccentric exercise. It is well known that the HR acceleration observed as a result of a muscular contraction occurs due to a vagal withdrawal, primarily in the beginning of the voluntary effort (i.e., $10 \mathrm{sec}.)^{14,23,40}$. In addition, this mechanism could be responsible for the HR increase until 30 seconds of contraction ${ }^{41}$. Thus, the divergent results observed in the literature could be due to the difference between the contraction length, since Horstmann et $\mathrm{al}^{2}$ and Mayer et al. ${ }^{3}$ evaluated the HR response during 1 minute of contraction, contrasting with the present study where the efforts was maintained for a mean of 12 seconds.

In addition, the angular velocity does not seem to exert influence on the HR response, since these were similar between the angular velocities applied for both concentric and eccentric contractions in the present study. These findings are in agreement with Haennel et al. ${ }^{14}$ who observed no differences in the HR response of young subjects for eccentric and concentric actions, respectively, performed in different angular velocities (ie., 30,90 and $150^{\circ} / \mathrm{s}$ ). Thus, the similarity of HR response between the tests performed in the present study could be attributed to a low or no influence by muscular structures (ie., muscular spindle and Golgi tendon organ, that are responsible for detecting the velocity of contraction, muscular length and muscular tension) on the magnitude of cardiovascular responses, when the concentric and eccentric contractions are performed at a short period of time and at $60 \%$ s or $120 \%$ s. This indicates that the HR responses to exercise of short periods it is not associated with the different neural mechanisms that occured during eccentric and concentric contraction.

The results of the present investigation suggest that the magnitude of torque and myoeletrical signal responses of older men are dependent on the type of muscular action (i.e, concentric and eccentric) and independent of angular velocity (i.e., 60 and $120^{\circ} / \mathrm{s}$ ), when they are performed at short lengths of time ( $12 \mathrm{sec}$.$) . Although the literature reports that the$ aging process causes a reduction of the muscular mass, EMG differences between the concentric and eccentric contractions were not observed. In addition, no difference in the magnitude of HR response was found in any of the exercises tested at short period, suggesting that it is independent of muscular action and angular velocity. As the tachycardia at the beginning of dynamic exercise is predominantly determined by the cardiac autonomic nerve activity ${ }^{42}$, evaluated by pharmacological 
blocking, the data from this study supports the theory that the magnitude of $\mathrm{HR}$ responses during maximal exercise at short durations depends on the central command and not for the mechanism of neural reflex ${ }^{43}$. Therefore, further studies about the effect of different velocities, time duration and muscular actions on cardiovascular and muscle responses in older subjects are needed.

The present study has limitations. Firstly, passive electrodes were used to collect EMG. However, we use the guidance of SENIAM $^{31}$ which recommends the use of electrodes $\mathrm{Ag} / \mathrm{AgCl}$ combined with a conductive gel that promotes a stable transmission of the signal with relative low noise. Still, our system had a pre-amplifier near the electrode, before connecting to the amplifier signal conditioner that promotes a good signal. And immediately after each test, the data were analyzed and if they had noises were discarded and a new test was performed. Secondly, due to the sample loss during the study, the final number of patients studied was small. However, the number was sufficient to detect differences in variables studied.

The practical applications of the present study refer to how important is to know about the overload that the eccentric and concentric exercises cause on the cardiovascular system. This study observed a larger torque and smaller EMG activity during the eccentric exercise however the magnitude of HR responses were similar, in other words, they caused the same cardiac impact when performed in short period of time. This indicates that the HR responses to exercise during short periods are not associated with the different neural peripheral mechanism that occurs during eccentric and concentric contraction. It will be necessary, in future studies, to investigate the stroke volume and blood pressure to determinate the cardiac output caused for this two types of contractions (i.e. eccentric and concentric). The knowledge of such impact is likely to turn the prescription of exercises safer and more effective, especially for the elderly population who is growing worlwide.

\section{Acknowledgments $: \because$}

To Tania de Fátima Salvini, UFSCar, for the use of the isokinetic dynamometer. We would also like to thank the Conselho Nacional de Desenvolvimento Científico e Tecnológico (CNPq) and Fundação de Amparo à Pesquisa do Estado de São Paulo (FAPESP).

\section{References $: \because$.}

1. Bross R, Storer T, Bhasin S. Aging and muscle loss. Trends Endocrinol Metab. 1999;10(5):194-8

2. Horstmann T, Mayer F, Fischer J, Marschmann J, Röcker K, Dickhuth HH. The cardiocirculatory reaction to isokinetic exercises in dependence on the form of exercise and age. Int J Sports Med. 1994;15 Suppl 1:S50-5.

3. Mayer F, Axmann D, Horstmann T, Niess A, Striegel H, Ruf J, et al. Metabolic and cardiocirculatory reactions after concentric and eccentric exercise of the shoulder. Int J Sports Med. 1999;20(8):527-31.

4. Kues JM, Rothstein JM, Lamb RL. The relationships among knee extensor torques produced during maximal voluntary contractions under various test conditions. Phys Ther. 1994;74(7):674-83.

5. Kellis E, Baltzopoulos V. Muscle activation differences between eccentric and concentric isokinetic exercise. Med Sci Sports Exerc. 1998;30(11):1616-23.

6. Wu Y, Li RC, Maffulli N, Chan KM, Chan JL. Relationship between isokinetic concentric and eccentric contraction modes in the knee flexor and extensor muscle groups. J Orthop Sports Phys Ther. 1997;26(3):143-9.

7. Holder-Powell HM, Rutherford OM. Reduction in range of movement can increase maximum voluntary eccentric forces for the human knee extensor muscles. Eur J Appl Physiol Occup Physiol. 1999;80(5):502-4.

8. Gür $H$, Gransberg L, vanDyke D, Knutsson E, Larsson L. Relationship between in vivo muscle force at different speeds of isokinetic movements and myosin isoform expression in men and women. Eur J Appl Physiol. 2003;88(6):487-96. Epub 2002 Dec 24.

9. Babault N, Pousson M, Ballay Y, Van Hoecke J. Activation of human quadriceps femoris during isometric, concentric, and eccentric contractions. J Appl Physiol. 2001;91(6):2628-34.

10. Horstmann T, Mayer F, Maschmann J, Niess A, Roecker K, Dickhuth HH. Metabolic reaction after concentric and eccentric endurance-exercise of the knee and ankle. Med Sci Sports Exerc. 2001;33(5):791-5

11. Linnamo V, Strojnik V, Komi PV. EMG power spectrum and features of the superimposed M-wave during voluntary eccentric and concentric actions at different activation levels. Eur $\mathrm{J}$ Appl Physiol. 2002;86(6):534-40
12. Huggett DL, Elliott ID, Overend TJ, Vandervoort AA. Comparison of heart-rate and bloodpressure increases during isokinectic eccentric versus isometric exercise in older adults. J Aging Phys Act. 2004;12(2):157-69.

13. Pincivero DM, Coelho AJ, Campy RM. Contraction mode shift in quadriceps femoris muscle activation during dynamic knee extensor exercise with increasing loads. J Biomech. 2008;41(15):3127-32.

14. Haennel RG, Snydmiller GD, Teo KK, Greenwood PV, Quinney HA, Kappagoda CT. Changes in blood pressure and cardiac output during maximal isokinetic exercise. Arch Phys Med Rehabil. 1992;73(2):150-5

15. Gerdle B, Wretling ML, Henriksson-Larsén K. Do the fibre-type proportion and the angular velocity influence the mean power frequency of the electromyogram? Acta Physiol Scand. 1988:134(3):341-6.

16. Koutedakis Y, Frischknecht R, Vrbová G, Sharp NC, Budgett R. Maximal voluntary quadriceps strength patterns in Olympic overtrained athletes. Med Sci Sports Exerc. 1995;27(4):566-72.

17. Kawakami $\mathrm{Y}$, Kubo K, Kanehisa H, Fukunaga T. Effect of series elasticity on isokinetic torqueangle relationship in humans. Eur J Appl Physiol. 2002;87(4-5):381-7.

18. Frontera WR, Meredith CN, O'Reilly KP, Knuttgen HG, Evans WJ. Strength conditioning in older men: skeletal muscle hypertrophy and improved function. J Appl Physiol. 1988;64(3):1038-44.

19. Kellis E, Baltzopoulos V. Isokinetic eccentric exercise. Sports Med. 1995;19(3):202-22.

20. Malfatti CA, Rodrigues SY, Takahashi ACM, Silva E, Menegon FA, Mattiello-Rosa SM, et al Análise da resposta da freqüência cardíaca durante a realização de exercício isocinético excêntrico de grupamento extensor de joelho. Rev Bras Fisioter. 2006;10(1):51-7.

21. Burden A, Bartlett R. Normalization of EMG amplitude: an evaluation and comparison of old and new methods. Med Eng Phys. 1999;21(4):247-57.

22. Cramer JT, Housh TJ, Evetovich TK, Johnson GO, Ebersole KT, Perry SR, et al. The relationships among peak torque, mean power output, mechanomyography, and electromyography in men and women during maximal, eccentric isokinetic muscle actions. Eur J Appl Physiol. 2002;86(3):226-32.

23. Rowell LB. Reflex control of the circulation during exercise. J Appl Physiol. 1992;12 Supp 1:S25-7. 
24. Mitchell JH, Kaufman MP, Iwamoto GA. The exercise pressor reflex: its cardiovascular effects, afferent mechanisms, and central pathways. Ann Rev Physiol. 1983;45:229-42.

25. Durand RJ, Kraemer RR, Hollander DB, Tryniecki JL, Wall M, Saxon L, et al. Different effects of concentric and eccentric muscle actions on plasma volume. J Strength Cond Res. 2003;17(3):541-8

26. Hollander DB, Durand RJ, Trynicki JL, Larock D, Castracane VD, Hebert EP, et al. RPE, pain, and physiological adjustment to concentric and eccentric contractions. Med Sci Sports Exerc. 2003;35(6):1017-25

27. Okamoto T, Masuhara M, Ikuta K. Cardiovascular responses induced during high-intensity eccentric and concentric isokinetic muscle contraction in healthy young adults. Clin Physiol Funct Imaging. 2006;26(1):39-44.

28. Vallejo AF, Schroeder ET, Zheng L, Jensky NE, Sattler FR. Cardiopulmonary responses to eccentric and concentric resistance exercise in older adults. Age Ageing. 2006;35(3):291-7.

29. Miller PC, Hall EE, Chmelo EA, Morrison JM, DeWitt RE, Kostura CM. The influence of muscle action on heart rate, RPE, and affective responses after upper-body resistance exercise. J Strength Cond Res. 2009;23(2):366-72.

30. Jaric S, Radosavljevic-Jaric S, Johansson $\mathrm{H}$. Muscle force and muscle torque in humans require different methods when adjusting for differences in body size. Eur $\mathrm{J}$ Appl Physiol. 2002;87(3):304-7.

31. Hermens HJ, Freriks B, Disselhorst-Klug C, Rau G. Development of recommendations for SEMG sensors and sensor placement procedures. J Electromyogr Kinesiol. 2000;10(5):361-74

32. Staudenmann D, Roeleveld K, Stegeman DF, van Dieën JH. Methodological aspects of SEMG recordings for force estimation - a tutorial and review. J Electromyogr Kinesiol. 2010;20(3):375-87
33. Silva E, Catai AM, Trevelin LC, Guimarães JO, Silva Jr LP, Silva LMP. Design of computerized system to evaluate the cardiac function during dynamic exercise [abstract]. Phys Med Biol. 1994;33:409.

34. Riemann BL, Myers JB, Lephart SM. Sensorimotor system measurement techniques. J Ath Train. 2002;37(1):85-98.

35. Stauber WT. Eccentric action of muscles: physiology, injury, and adaptation. Exerc Sport Sci Rev. $1989 ; 17: 157-85$

36. Babault N, Pousson M, Michaut A, Ballay Y, Hoecke JV. EMG activity and voluntary activation during knee-extensor concentric torque generation. Eur J Appl Physiol. 2002;86(6): 541-7.

37. Tian SL, Liu Y, Li L, Fu WJ, Peng CH. Mechanomyography is more sensitive than EMG in detecting age-related sarcopenia. J Biomech. 2010; 43(3):551-6.

38. Klass M, Baudry ES, Duchateau J. Voluntary activation during maximal contraction with advancing age: a brief review. Eur J Appl Physiol. 2007;100(5):543-51.

39. Overend TJ, Versteegh TH, Thompson E, Birmingham TB, Vandervoort AA. Cardiovascular stress associated with concentric and eccentric isokinetic exercise in young and older adults. J Geronto A Biol Sci Med Sci. 2000;55(4):B177-82.

40. Maciel BC, Gallo Junior L, Marin Neto JA, Martins LE. Autonomic nervous control of the hear rate during isometric exercise in normal man. Pflugers Arch. 1987;408(2):173-7.

41. Maciel BC, Gallo L Jr, Marin Neto JA, Lima Filho EC, Martins LE. Autonomic nervous control of the heart rate during dynamic exercise in normal man. Clin Sci (Lond). 1986;71(4):457-60.

42. Wakasugi R, Nakamoto T, Matsukawa K. The effects of adrenalectomy and autonomic blockades on the exercise tachycardia in conscious rats. Auton Neurosci. 2010;155(1-2):59-67.

43. Matsukawa K, Nakamoto T, Inomoto A. Gadolinium does not blunt the cardiovascular responses at the onset of voluntary static exercise in cats: a predominant role of central command. Am J Physiol Heart Circ Physiol. 2007;292(1):H121-9. 